\title{
El desarrollo del curriculum universitario en tiempos de COVID19: oportunidad y contrariedad
}

\section{The development of the university curriculum in times of COVID19: opportunity and setback}

\section{Sonia M. Araujo}

https://orcid.org/0000-0002-7692-1821

saraujo@fch.unicen.edu.ar

Universidad Nacional del Centro de la

Provincia de Buenos Aires | Argentina

\section{PRESENTACIÓN}

La crisis epidemiológica a nivel mundial, producto de la pandemia Covid19 alteró, como nunca hubiéramos imaginado, la vida en sociedad. De un mundo totalmente interconectado se pasó a un distanciamiento social para la prevención de los contagios en el que las relaciones sociales en diferentes escalas geográficas, tanto en los ámbitos público como privado, comenzaron a ser mediados a través de las tecnologías digitales. En la República Argentina el DNU Nº 297/20 estableció el aislamiento social, preventivo y obligatorio (ASPO) a partir del 20 de marzo de 2020 en el marco de la declaración de pandemia del Covid19 por parte de la Organización Mundial de la Salud y de asumir a ésta como un derecho inalienable del Estado.

Antes del ASPO, por razones sanitarias, en el territorio nacional, desde el Ministerio de Educación ya habían sido suspendidas las clases presenciales en los niveles inicial, primario, secundario y superior no universitario (Resolución N 108/20). En el caso de las instituciones universitarias públicas y privadas, el Ministerio de Educación en esta situación de excepcionalidad recomendó la adecuación de la actividad académica presencial conforme a las recomendaciones del Ministerio de Salud a través de la adecuación del calendario académico, la utilización de diferentes medios para enseñar -medios de comunicación, campus virtuales o cualquier entorno digital- y llevar a cabo la enseñanza reduciendo 
la cantidad de estudiantes en las aulas hasta una ocupación del 50 por ciento de su capacidad (Resolución N 104/20).

En este contexto las instituciones respondieron rápidamente, sin una apropiada planificación y con escaso tiempo para realizar las modificaciones en el trabajo de docencia ante la urgencia de los calendarios académicos establecidos para el inicio de las clases presenciales. El rápido ajuste fue posible merced al trabajo persistente que se ha venido realizando con el propósito de integrar la educación mediada por tecnologías digitales en el ámbito universitario a través de la creación de carreras de educación a distancia o de propiciar el enriquecimiento de la enseñanza a través de la implementación de aulas virtuales como una opción complementaria a las clases presenciales. El reconocimiento, la legitimación y la institucionalización de estas propuestas, a su vez, se consagró recientemente a través de la evaluación externa de los Sistemas Institucionales de Educación a Distancia (SIED) por la Comisión Nacional de Evaluación y Acreditación Universitaria (CONEAU) para su posterior validación por la Secretaría de Políticas Universitarias (SPU) en el marco de la Resolución N²641/17. Estas áreas institucionales tuvieron un rol esencial en este contexto de excepcionalidad, pues crearon las aulas virtuales para los espacios curriculares a fin de iniciar -en el caso de estudiantes de primer año- o de continuar la formación en carreras de grado y posgrado y ofrecieron instancias de capacitación a través de webinares o cursos destinados a brindar una formación pedagógica y tecnológica capaz de sostener la adaptación de las propuestas didácticas a los entornos virtuales de enseñanza y aprendizaje.

Cabe destacar que, en el caso de las instituciones universitarias públicas, como lo expresó tempranamente en el mes de abril el Consejo Interuniversitario Nacional (CIN), significó asumir la necesidad de garantizar la continuidad pedagógica y del trayecto académico "generando las condiciones de igualdad de oportunidades en el acceso a los recursos tecnológicos para desarrollar la enseñanza virtual con becas, acuerdos de conectividad con las prestadoras de servicio, flexibilizando los regímenes de cursado, implementando acompañamientos tutoriales y asistiendo materialmente a quienes más lo necesitan" (CIN, 2020).

En ese marco general este trabajo, a modo de ensayo, expone una serie de reflexiones a partir de la recuperación de la palabra de docentes que debieron enfrentar abruptamente esta realidad alterada que colocó a la docencia en el centro de la escena. pone una serie de reflexiones a partir de la recuperación de la palabra de docentes que debieron enfrentar abruptamente esta realidad alterada que colocó a la docencia en el centro de la escena. 
Si bien se trata de un cambio reactivo, urgido por circunstancias externas y ajenas a los establecimientos universitarios, la excepcionalidad en tiempos de pandemia movilizó la reflexión y la acción, ausente mientras todo se hacía del mismo modo, en torno a cuestiones nodales del proceso formativo: qué, para qué y cómo enseñar; cuál es la vinculación entre aquello dispuesto para la enseñanza y la práctica profesional de los futuros graduados; cómo integrar el aprendizaje de la práctica durante la formación; cómo evaluar y acreditar aprendizajes; qué hacer ante la heterogeneidad y la desigualdad del estudiantado; entre otras. Contrariamente a los planteamientos que se venían realizando, fundamentalmente desde la década de 1990, en esta oportunidad la actividad docente le disputó el tiempo a las tareas de investigación, siempre más valoradas en cuanto símbolo de prestigio de la profesión académica. En este sentido, este germen de la reflexión en torno a la enseñanza, en esta ocasión extendida al conjunto de las diversas disciplinas universitarias y de las orientaciones adoptadas en la formación -de corte académico y profesionalpermite recuperar la afirmación de Clark para quien "frente a todas las barreras que se oponen a la innovación, los establecimientos y los sistemas académicos pueden ser muy adaptables" (Clark, 1983: 263).

\section{EL CONTEXTO}

La organización de ideas que se presenta a continuación es producto de la participación de 54 docentes de diferentes facultades en un foro planificado en el seminario "Problemáticas político pedagógicas de la educación superior" en el marco de la Especialización en Docencia Universitaria de la Universidad Nacional de La Plata.

\section{La organización de ideas que se presenta a continuación es producto de la participación de $\mathbf{5 4}$ docentes de diferentes fa- cultades en un foro planificado en el seminario "Problemáticas político pedagógicas de la educación superior" en el marco de la Especialización en Docencia Universitaria de la Universidad Nacional de La Plata.}

El seminario aborda como eje la significación que adquiere la definición de proyectos político-pedagógicos en las instituciones universitarias públicas que garanticen el derecho a la educación superior a partir del cambio de la Ley de Educación Superior $N^{\circ} 24.521$ en 2015 (Ley N ${ }^{\circ} 27.204$ ) y de las definiciones de la Conferencia Regional de Educación Superior (CRES) celebrada en 2018 que establece la educación superior como un derecho humano, un bien público social y un deber del Estado.

El foro se estructuró a partir del informe "COVID-19 y educación su- 
perior: De los efectos inmediatos al día después. Análisis de impactos, respuestas políticas y recomendaciones" (2020) de IESALC-UNESCO que plantea los impactos inmediatos de la pandemia en el sector de la educación superior universitaria, tanto para los distintos actores como para las instituciones y el sistema en su conjunto; analiza las acciones que han emprendido gobiernos e Instituciones de Educación Superior (IES) para garantizar el derecho a la educación superior durante la pandemia; y formula algunas consideraciones y recomendaciones para encarar la reapertura de las IES. A partir del eje del seminario, el propósito fue reflexionar, compartir e intercambiar ideas en torno a los efectos de la pandemia con relación a los problemas relativos a la permanencia y la graduación del estudiantado -y su contracara el abandono- recuperando la experiencia individual y colectiva en el ejercicio de la docencia en la institución.

\section{A partir del eje del seminario, el propósito fue reflexionar, compartir e intercambiar ideas en torno a los efectos de la pandemia con relación a los problemas relativos a la perma- nencia y la graduación del estudiantado -y su contracara el abandono- recuperando la experiencia individual y colecti- va en el ejercicio de la docencia en la institución.}

Las preguntas orientadoras del debate buscaron relevar el comportamiento de los estudiantes en el nuevo formato de enseñanza y el cambio en el trabajo docente. En este texto se avanza en torno a la organización de algunas reflexiones preliminares referidas a los cambios en el trabajo como docente a partir del desarrollo del curriculum en el entorno virtual que podrían constituirse en fuente de hipótesis para profundizar en estudios de mayor alcance, tanto en instituciones particulares como en diversas instituciones a través de estudios comparados.

\section{DEL CURRICULUM PRESENCIAL A LA VIRTUALIZACIÓN DEL CURRICULUM}

En el campo curricular, desde la década de 1960 y particularmente en el modelo de proceso desarrollado por Stenhouse $(1984 ; 1987)$, el curriculum es concebido como una hipótesis que ha de ponerse a prueba en las instituciones educativas. No se trata, como aún suele pensarse, de un documento que se aplica a través de la enseñanza en las aulas. Según el autor "Un C. [curriculum] es una tentativa para comunicar los principios y rasgos esenciales de un propósito educativo, de forma tal que permanezca abierto a discusión crítica y pueda ser trasladado efectivamente a la práctica" (Stenhouse, 1984: 29). Con otras palabras, amplía y expresa esta idea, diciendo que "cons- 
tituye una especificación que resulta hipotética, abierta a interrogantes y a comprobación y dentro de la cual se construye y gestiona el conocimiento (Stenhouse, 1987: 93). De manera que el problema del curriculum, para el autor, es el de relacionar ideas con realidades, el de ligar el curriculum concebido, o en el papel, con el curriculum en clase.

En la universidad, el curriculum propone contenidos -conocimientos, habilidades, prácticas, actitudes, valores y normas- de una disciplina para el aprendizaje de una práctica profesional específica a través de diferentes formatos (Camilloni, 2016). El curriculum universitario implica el ingreso a un campo disciplinario y profesional, a un ambiente cultural particular configurado por creencias más o menos compartidas -producto de las tensiones entre perspectivas de grupos internos y externos diversos- en torno a los problemas, la teoría, las técnicas de intervención e investigación, los contenidos valiosos, el rol de los profesionales en una sociedad heterogénea y desigual, el valor de la práctica pre profesional en el aprendizaje de esa profesión y los mejores modos de integrarla en la propuesta formativa. Para los estudiantes el proceso de aprendizaje en la universidad supone, entonces, el acceso a un lenguaje especializado y a un modo particular de desarrollo del conocimiento y del ejercicio profesional dentro de esa especialidad. De modo que el problema del acceso, la permanencia y la apropiación de conocimientos socialmente relevantes envuelve un doble desafío: ingresar y descifrar los códigos del ambiente cultural propio de la universidad y del ambiente cultural propio de una disciplina y su ejercicio profesional idiosincrásico (Araujo, 2008). En este último caso el diseño curricular establece un trazado anticipado de una trayectoria académica estudiantil teniendo en cuenta alguna representación de los estudiantes que lo transitarán y que, en el modo como se contemplen sus diferencias sociales, culturales, económicas, étnicas, de género, de edad, de capacidades, tendrá efectos diversos en los procesos de inclusión educativa en las instituciones.

\section{EL DESARROLLO CURRICULAR EN ENTORNOS VIRTUALES DESDE LA PERSPECTIVA DEL PROFESORADO}

La enseñanza en tiempos de pandemia alteró las condiciones sobre las cuales se pensó el desarrollo curricular: desde currículos oficiales -comúnmente denominados planes de estudio- pensados para ser implementados en las aulas a través de la interacción cara a cara con estudiantes en clases presenciales, se pasó a la enseñanza en entornos virtuales, como se dijo, con escaso tiempo para una planificación acorde a las nuevas demandas de la enseñanza y el aprendizaje.

El cambio que significó el traslado de la educación presencial a la denominada enseñanza remota es caracterizado por los docentes como "virtualidad obligada", "experiencia forzada", "adaptación repentina e imprevista", "adaptación veloz", "adaptación en tiempo record", "virtualización compulsiva", entre las múltiples expresiones utilizadas. 
El cambio que significó el traslado de la educación presencial a la denominada enseñanza remota es caracterizado por los docentes como "virtualidad obligada", "experiencia forzada", "adaptación repentina e imprevista", "adaptación veloz", "adaptación en tiempo record", "virtualización compulsiva", entre las múltiples expresiones utilizadas.

Cabe destacar que quienes estuvieron en mejores condiciones de transitarlo fueron aquellos que tenían formación en educación y nuevas tecnologías -en este caso por haber cursado el seminario Educación a Distancia y Nuevas Tecnologías-, habían realizado cursos de capacitación ofrecidos por el área de Educación a Distancia y Tecnologías de la Universidad, contaban con "aulas web" como complemento de las clases presenciales, o habían tenido alguna experiencia de trabajo con el Centro de Producción Multimedial (CEPROM) en la elaboración de materiales didácticos. En este sentido, se valora la decisión política de la Universidad de garantizar la continuidad pedagógica así como el acompañamiento institucional para la adaptación de los cursos al entorno virtual, situación que favoreció aún más a docentes responsables de espacios curriculares que se cursan durante la segunda mitad del ciclo académico.

En las voces del cuerpo docente, altamente heterogéneo según las disciplinas y subdisciplinas que enseñan en diferentes proyectos formativos, se puede vislumbrar dos ideas que dan cuenta de la situación actual y que se configuran como las dos caras de una misma moneda: el desarrollo curricular en la excepcionalidad como oportunidad y el desarrollo curricular en la excepcionalidad como contrariedad.

En las voces del cuerpo docente, altamente heterogéneo según las disciplinas y subdisciplinas que enseñan en diferentes proyectos formativos, se puede vislumbrar dos ideas que dan cuenta de la situación actual y que se configuran como las dos caras de una misma moneda: el desarrollo curricular en la excepcionalidad como oportunidad y el desarrollo curricular en la excepcionalidad como contrariedad.

En el primer caso, la excepcionalidad como oportunidad, alude a que se trata de un contexto que propició la reflexión y la modificación de la enseñanza en varios sentidos. Por un lado, en lo que refiere a los aspectos didácticos, en los espacios curriculares estimuló la revisión de los programas en cuanto a los contenidos seleccionados; de los modos de enseñanza, posibilitando la experimentación de nuevos recursos y alternativas; de los límites y alcances de la enseñanza 
en entornos virtuales de ciertos contenidos -referidos a la práctica en instituciones externas y en laboratorios-, en un trabajo colaborativo para coordinar las acciones de sus integrantes. Desde este punto de vista se afirma la utilización de aulas virtuales en plataformas Moodle y Classroom, de múltiples plataformas para la comunicación sincrónica (Zoom, Jit.si, Meet, Webex) y de las redes sociales con fines de comunicación e intercambio (Whatsapp, Facebook). Por el otro, con respecto a los estudiantes, ayudó al reconocimiento de las características de los "estudiantes reales" en cuanto a su capital económico y cultural, su situación familiar, sus capacidades, sus estados emocionales. Este reconocimiento -que en la enseñanza presencial estaba ausente- obedeció a la necesidad de estar al tanto respecto de las posibilidades de acceso a las tecnologías digitales (conectividad y dispositivos) a fin de garantizar el derecho a la educación superior en un marco de igualdad de oportunidades, evitando situaciones de discriminación que terminarían reproduciendo las desigualdades sociales y educativas preexistentes. La importancia otorgada a la presencia estudiantil en los entornos virtuales a fin de cumplimentar los objetivos de los espacios curriculares, dio lugar a diferentes estrategias de obtención de información sobre sus condiciones particulares para el estudio así como de acompañamiento didáctico y, en ocasiones, psicológico, a fin de promover la permanencia.

En el segundo caso, la excepcionalidad como contrariedad, alude al modo como se llevaron a cabo las acciones anteriores y la dificultad de ser sostenido en el tiempo bajo las mismas condiciones. Por un lado, implicó mayor tiempo de dedicación a la actividad de docencia insumido en la organización de la enseñanza, las reuniones del equipo docente para coordinar tareas, el acompañamiento de los estudiantes y la capacitación para integrar las herramientas tecnológicas en los planteamientos didácticos. En algunos casos las acciones que llevaron a cabo superaron las dedicaciones con las que contaban, situación expresada como "sobre exigencia", "sobrecarga", "desgaste", "duplicación o triplicación de horas de trabajo", "trabajo arduo y más demandante", más aún en el caso de cursos masivos. Se señala que en esta realidad compleja no hubo posibilidad de expresar cómo llevar a cabo la virtualización, no se consideró la falta de conocimientos e información para enseñar en línea ni las situaciones personales e institucionales del cuerpo docente, EI contenido del trabajo abarca el diseño de actividades y materiales nuevos, la producción de videos y de tutoriales, la elaboración y corrección de trabajos prácticos y de parciales para la "virtualidad", las tareas de retroalimentación, la atención diaria de foros, la respuesta de correos electrónicos, la familiarización con las plataformas, las videoconferencias y videollamadas, las contestaciones de mensajes de whatsapp, todas actividades relativas al acompañamiento de los procesos de aprendizaje y de las reacciones socioafectivas y emocionales manifestadas por grupos o alumnos particulares. Por otro lado, se trata de prácticas cargadas de incertidumbre frente a algunos es- 
tudiantes que no participan de las videoconferencias y, si participan, no encienden sus cámaras, o no responden los correos electrónicos, en ocasiones por dificultades con la conectividad y por no disponer de los dispositivos adecuados para hacerlo. Este proceso de comunicación mediado por las tecnologías digitales, a su vez, no ofrece la necesaria retroalimentación de los procesos de enseñanza que se produce en las clases presenciales a través de las manifestaciones gestuales y verbales de los estudiantes. La cualidad de incertidumbre propia de la enseñanza, a la cual refiere Jackson (2002) aún en los entornos presenciales, se potencia en un territorio desconocido como docente y sobre el cual también se carece de experiencia como estudiante.

\section{REFLEXIONES PRELIMINARES. UNA REVISITA DEL ESCENA- RIO ACTUAL}

Las experiencias docentes anteriores, aunque con algunas variantes, seguramente expresan de manera bastante fiel lo que sucedió y está sucediendo en el conjunto del sistema. En este sentido, la valoración de la responsabilidad social asumida por las instituciones universitarias públicas ante la crisis epidemiológica también amerita indagaciones e investigaciones acerca de las condiciones y el modo como se está garantizando la continuidad pedagógica y, sobre todo, en la planificación de un futuro todavía incierto. La integración de las tecnologías digitales para enseñar y aprender en la "nueva normalidad", en la que la enseñanza presencial probablemente seguirá afectada y alterada por el necesario distanciamiento social, requiere de un marco reflexivo y evaluativo de la etapa transitada si se pretende garantizar el derecho a la educación superior.

\section{La integración de las tecnologías digitales para enseñar y aprender en la "nueva normalidad", en la que la enseñanza presencial probablemente seguirá afectada y alterada por el necesario distanciamiento social, requiere de un marco reflexi- vo y evaluativo de la etapa transitada si se pretende garantizar el derecho a la educación superior.}

La estrategia actual da cuenta de la adopción de múltiples formatos, resultado de procesos de autogestión individual y grupal -más allá de las decisiones institucionales para acompañar el trabajo de los docentes-, en la mediación pedagógico-didáctica de diseños curriculares elaborados para la educación presencial. No se trata de educación a distancia. Las carreras que se crean para su implementación bajo la opción pedagógica y didáctica a distancia, en la actualidad, siguen criterios y estándares nacionales. Es el caso particular 
de las carreras de grado que forman parte del artículo 43 de la Ley de Educación Superior $N^{\circ} 24.521 / 95$ y de las carreras de posgrado que deben ser acreditadas por la Comisión Nacional de Evaluación y Acreditación Universitaria (CONEAU). En el origen mismo de la propuesta formativa, el diseño tecnopedagógico contempla todas las dimensiones que han de atenderse cuando la enseñanza y el aprendizaje transcurren en entornos virtuales. Ciertos nudos problemáticos, visibilizados en la actualidad, como el acceso a conectividad y a dispositivos pertinentes por parte de los estudiantes, la enseñanza y el aprendizaje de la práctica dentro o fuera de la universidad, la formación de los docentes para enseñar en línea, la conformación de plantas docentes acorde a la cantidad de estudiantes así como la evaluación y la acreditación, se prevén y forman parte de los criterios y estándares de evaluación.

En el contexto de autonomía que gozan las instituciones universitarias, se requiere una autoevaluación institucional, focalizada, democrática, participativa, deliberativa y permanente de las decisiones y sus múltiples efectos -en docentes, estudiantes ingresantes y avanzados, no docentes, personal de gestión, instituciones de la sociedad civil, entre otros-, a fin de crear regulaciones que conjuguen calidad e inclusión educativa. Este abordaje institucional tendrá significación para la creación de regulaciones nacionales que, sin interferir la autonomía de las instituciones, brinden un marco general compartido, como política pública, con el mismo propósito.

El camino recorrido da cuenta de un trabajo sostenido y sobre exigido por parte del cuerpo académico y de un compromiso de los estudiantes en sostener estos cambios que alteraron el contrato pedagógico implícito en la educación presencial. En esta nueva realidad la coordinación de la enseñanza entre docentes del mismo o de diferentes espacios curriculares, el reconocimiento de estudiantes con realidades personales específicas y la movilización de los modos de enseñar heredados -caracterizados como "individualistas" y "enquistados"- son pilares fundamentales para la mejora y democratización de los procesos formativos. Se trata de indicios que aún bajo condiciones laborales más o menos precarias, como fue señalado en el inicio, podrían derivar en la institucionalización de procesos innovadores de los diseños curriculares y las prácticas pedagógicas. No obstante, ante la heterogeneidad de realidades y situaciones institucionales también es cierto que es preciso relevar otras voces sobre lo que sucede. Los indicios innovadores también coexisten con otros formatos en los que la enseñanza presencial se trasladó sin demasiados cambios a la virtualidad: aulas como repositorios de bibliografía, videoconferencias sin interacción, exigencia de múltiples y complejas actividades para resolver, diferentes tipos de vinculación con los estudiantes, que en lugar de favorecer la permanencia provocaron el abandono en un contexto de crisis económica y laboral, con pérdida o interrupción del trabajo, en realidades configuradas sobre la desigualdad. 
Los indicios innovadores también coexisten con otros formatos en los que la enseñanza presencial se trasladó sin demasiados cambios a la virtualidad: aulas como repositorios de bibliografía, videoconferencias sin interacción, exigencia de múltiples y complejas actividades para resolver, diferentes tipos de vinculación con los estudiantes, que en lugar de favorecer la permanencia provocaron el abandono en un contexto de crisis económica y laboral, con pérdida o interrupción del trabajo, en realidades configuradas sobre la desigualdad.

En este escenario inédito se abre un abanico de interrogantes cuya respuesta requiere del análisis y la sistematización de experiencias con el propósito de evaluar los efectos de las acciones que se están llevando a cabo. Desde el punto de vista del desarrollo curricular cobra relevancia la reflexión, producción y socialización por parte de los docentes con el propósito de aprender mientras se enseña. $Y$ también para comenzar a compartir, actualmente bajo las mediaciones tecnológicas y, hacia a delante bajo el modo que se construya en la nueva normalidad, todavía incierta. Desde el punto de vista de la gestión, resulta imprescindible desarrollar procesos de autoevaluación que integren esas experiencias, lo cual también es una oportunidad para superar enfoques burocráticos afines y funcionales a contextos rutinarios.

Como plantea de Souza Santos (2020), al hablar de la pedagWogía del virus en un sentido sociopolítico amplio, "la pandemia es una ventana de oportunidad para empezar a cambiar las cosas". En el caso particular de la universidad, con un rol significativo en la producción y reproducción del conocimiento científico-tecnológico, filosófico y artístico, quizá sea una oportunidad para repensar los modos de esa producción y transmisión, La pandemia ha visibilizado las desigualdades sociales y económicas existentes en las sociedades y también los límites de la ciencia que aún no ha podido encontrar la vacuna para combatir el virus. La recuperación de otros saberes respetuosos de la naturaleza propios de grupos marginados de la sociedad y de la educación superior así como la reflexión ética sobre la creación y utilización del conocimiento científico tecnológico deberían formar parte de la formación de los futuros profesionales y ciudadanos universitarios: ¿conocimientos y tecnologías para qué?, ¿de quién/es?, ¿para quién o a beneficio de quién? La cuestión ambiental como dimensión transversal de los diseños curriculares se ha planteado desde hace varias décadas pero no se ha generalizado. El mWodelo de desarrollo actual atenta contra la vida humana y en esto la universidad debería poder expresarlo y abordarlo en sus diferentes campos disciplinares al menos si no queremos que ocurra lo expresado por de Souza Santos para 
quien, de seguir así, "no vamos a entrar en un nuevo período de pos pandemia, sino de pandemia intermitente". Y cierro con el título de la entrevista que interpela a una multiplicidad de actores políticos, sociales y también universitarios: "El virus es un pedagogo que nos intenta decir algo. El problema es saber si vamos a escucharlo". 


\section{REFERENCIAS BIBLIOGRÁFICAS}

Araujo, S. (coord.) (2008). Formación universitaria y éxito académico: Disciplinas, Estudiantes y Profesores. Tandil: UNICEN.

Camilloni, A. (2016). Tendencias y formatos en el currículo universitario. En Itinerarios educativos, $N^{\circ}$ 9, pp. 1-29. Disponible en: https://bibliotecavirtual.unl.edu.ar/publicaciones/index.php/Itinerarios/issue/view/610

Clark, B. (1983). El sistema de educación superior. Una visión comparativa internacional. México: Nueva Imagen.

De Souza Santos, B. (2020). El virus es un pedagogo que nos intenta decir algo. El problema es saber si vamos a escucharlo. Entrevista realizada por $\mathrm{M}^{\mathrm{a}}$ Ángeles Fernández y J. Marcos. Ethic. Recuperado de: https://ethic.es/entrevistas/boaventura-de-sousa-santos-coronavirus/. Fecha de consulta: 12-08-2020.

IESALC-UNESCO (2020). COVID-19 y educación superior: De los efectos inmediatos al día después Análisis de impactos, respuestas políticas y recomendaciones. Caracas: UNESCO-IESALC.

Jackson, Ph. (2002). Práctica de la enseñanza. Buenos Aires: Amorrortu.

Stenhouse, L. (1984). Investigación y desarrollo del curriculum. Madrid: Morata.

Stenhouse, L. (1987). La investigación como base de la enseñanza. Selección de textos por J. Rudduck y D. Hopkins. Madrid: Morata.

\section{FUENTES DOCUMENTALES}

República Argentina. Aislamiento social, preventivo y obligatorio. Decreto Presidencial N²97/2020. Boletín Oficial de la República Argentina.

Ministerio de Educación. Resolución N 108/2020. Boletín Oficial de la República Argentina.

Ministerio de Educación. Resolución Nº104/2020. Boletín Oficial de la República Argentina.

Ministerio de Justicia y derechos humanos. Ley de Educación Superior $N^{\circ} 24.521 / 1995$ y Ley modificatoria $N^{\circ} 27.204 / 15$. Información Legislativa. 